\title{
FRATURAS E DESENVOLVIMENTO DE UNIDADES GEOMORFOLÓGICAS CÔNCAVAS NO MÉDIO VALE DO RIO PARAÍBA DO SUL*
}

\author{
ANDRÉ S. AVELAR*** \& ANA L. COELHO NETTO**
}

\begin{abstract}
JOINTS AND HOLLOW DEVELOPMENT IN THE MIDDLE VALLEY OF PARAÍBA DO SUL RIVER, SOUTHEASTERN BRAZIL. Field observations, together with detailed geologic mapping $(1: 10,000)$, topographic readings at same sacale and photointerpretation $(1: 25,000)$, conducted on the hilly lowlands, under distinct lithologies, have demonstrated the strong role of joint systems of underlying bedrock in controlling the development of concave hillslope morphology. One suggests that certain jointing conditions in weathered bedrock would favour the exfiltration of subsurface flows and channel formation due to erosion mechanism by critical pore-pressure on the seepage face (seepage erosion). Channel evolution along the joints would trigger mass movement (slump type) on the lateral slopes and geadwatems, provideng the formation and expansion of structural concavities.
\end{abstract}

Keywords: Joints, hollows, seepage erosion.

\begin{abstract}
RESUMO Observações de campo junto com mapeamentos geológicos de detalhe (1:10.000), leituras de cartas topográficas na mesma escala e foto interpretação $(1: 25.000)$, conduzidos nas áreas de colinas rebaixadas, sob litologias distintas, demostram o forte papel exercido pelo sistema de fraturas do substrato rochoso no controle do desenvolvimento das formas côncavas nas encostas. Sugere-se que certas condições de fraturamento em matriz rochosa alterada favoreceriam a exfiltração (exfiltration) de fluxos d'agua subsuperficiais e a formação de canal, devido ao mecanismo de erosão por poro-pressões críticos nas faces de vazamento (seepage erosion). A evolução dos canais ao longo do fraturamento detonaria movimentos de massa (tipo slump) nas encostas laterais e cabeceiras, propiciando a formação e o desenvolvimento de concavidades estruturais.
\end{abstract}

Palavras-chaves: Fraturas, morfologia de encostas, erosão por água superficial.

INTRODUÇÃO O desenvolvimento do relevo envolve a formação de vales, onde as unidades geomorfológicas côncavas constituem zonas preferenciais de convergência de água e sedimentos. Desde Davis (1900), Büdel (1982) e outros, a dissecação dos fundos de vale tem sido associada ao trabalho de fluxos de água concentrados, cuja resultante é expressa nas formas de canais com bordas bem definidas. A literatura geomorfológica evidencia a existência de unidades côncavas com distintas configurações, em regiões sob condições climáticas e geológicas variadas, refletindo uma certa diversidade quanto a natureza dessas concavidades.

A terminologia associada à morfologia côncava do relevo é curiosamente ampla. Já, Davis (1900) referia-se às depressões laterais dos vales "conseqüentes" como sendo hollow. Mais tarde, Hack \& Godlett (1960) e Hack (1960) usaram o termo hollows para expressar as zonas de convergência de fluxos, delineados pelas curvas de nível côncavas para fora, no domínio das encostas. Ao hollow definido por Hack, corresponderiam os dells citados em Büdel (1982) e Mills (1989), as "rampas" definidas por Meis \& Monteiro (1979), os dambos descritos por Mckel (1974) e os bogcirques de Dzulynski \& Pekala (1980). Para indicar, particularmente, as concavidades sem canais em zonas de cabeceira de drenagem, Tsukamoto et al. (1982) empregaram o termo "bacia de ordem zero". Considerando que tais unidades podem reproduzir-se em diferentes escalas e articular na paisagem compondo um sistema de hierarquia e densidade variável, Dietrich et al. (1986) referem-se às mesmas como vales não-canalizados (unchanneled valleys).

$A$ expressão unchanneled valley, além de incluir a unidade côncava das encostas, refere-se a um sistema de drenagem através do qual os principais fluxos d'agua superficiais e/ou subsuperficiais convergem para a rede de drenagem canalizada (Horton 1945, Dunne 1970, Anderson \& Burt 1978, Coelho
Netto 1985, Fernandes 1990 e outros). Esta rede de drenagem canalizada pode incluir, além do sistema principal de canais interconectados, outros canais que se desenvolvem desconectados, estando estes últimos associados à retomada de dissecação de vales anteriormente não-canalizados (Oliveira \& Meis 1985, Montgomery \& Dietrich 1988). No médio Vale do Rio Paraíba do Sul, observa-se que, em certas áreas, os dois sistemas de canais, desconectados e interconectados, tendem a se juntar, especialmente pelo avanço remontante da rede principal, particularmente, em direção aos eixos das concavidades tributárias das cabeceiras de drenagem (Coelho Netto et al. 1988). Sob determinadas condições locais, a extensão dos canais pode prolongar-se além dos divisores da bacia, capturando sistemas de drenagem adjacentes canalizados ou não (Coelho Netto \& Fernandes 1990).

Estudos anteriores elaborados a partir de mapeamentos geológicos de detalhe, em 1:50.000 (regional) e 1:25.000 (local), junto com o levantamento em base topográfica (1:25.000) das orientações dos canais que drenam a bacia do Rio Bananal, afluente do Rio Paraíba Sul no seu médio curso, mostram que o sistema regional de canais é fortemente controlado pelas estruturas do substrato geológico, predominando as direcões que seguem a atitude regional das camadas geológicas, NE-SW, e as principais orientações do fraturamento regional, NW-SE (Almeida et al. 1989 e Lopes et al. 1989). Tais resultados confirmaram as observações anteriores de Agostinho (1969). Neste trabalho, procura-se ampliar os argumentos de campo que possam melhor fundamentar a análise do papel do substrato geológico no controle do desenvolvimento das formas côncavas do relevo, ou seja, dos vales canalizados e nãocanalizados. Focaliza-se o fraturamento das rochas no direcionamento dos vales, as encostas laterais e cabeceiras de drenagem dos vales canalizados principais. Pretende-se em última análise, discutir o modelo conceituai sobre a formação

\footnotetext{
* Pesquisa financiada pelo $\mathrm{CNPq}$

** Laboratório de Geo-Hidrologia, Departamento de Geografia, UFRJ, Ilha do Fundão, CEP 21910-000, Rio de Janeiro, RJ, Brasil
} 
de vales estruturais controlados por fraturas, tendo em vista orientar futuros estudos de campo que possam subsidiar os modelos matemáticos em bases físicas, para a previsão das respostas hidrológicas e erosivas que governam o desenvolvimento dos vales ou, em termos práticos, que definem as zonas potenciais de instabilidade nas encostas.

\section{LOCALIZAÇÃO E CONDIÇÕES AMBIENTAIS A}

área de estudo situa-se na região do Médio Vale do Rio Paraíba do Sul, Município de Bananal, extremo leste do Estado de São Paulo, sendo delimitada pelos paralelos $22^{\circ} 35^{\prime} \mathrm{e} 22^{\circ} 45^{\prime} \mathrm{S}$ e meridianos $44^{\circ} 15^{\prime}$ e $44^{\circ} 25^{\prime} \mathrm{W}$ (Fig. 1). Prevalece um clima mesotérmico do tipo Cwa de Köppen, com temperatura média anual em torno de $20^{\circ} \mathrm{C}$, estando a região de Bananal numa faixa de pluviosidade anual entre 1250-1500 mm (Brandalise et al. 1976). A análise de uma série de 18 anos na Estação de Bananal mostra que $25 \%$ dos meses mais chuvosos ultrapassam $191 \mathrm{~mm}$. As chuvas tendem a concentrar-se nos meses de verão, quando ocorrem os eventos de maior intensidade em resposta à atuação de frentes frias, cuja freqüência é responsável pelas variações de pluviosidade anual (Coelho Netto \& Santos 1979, Meis et al. 1981).

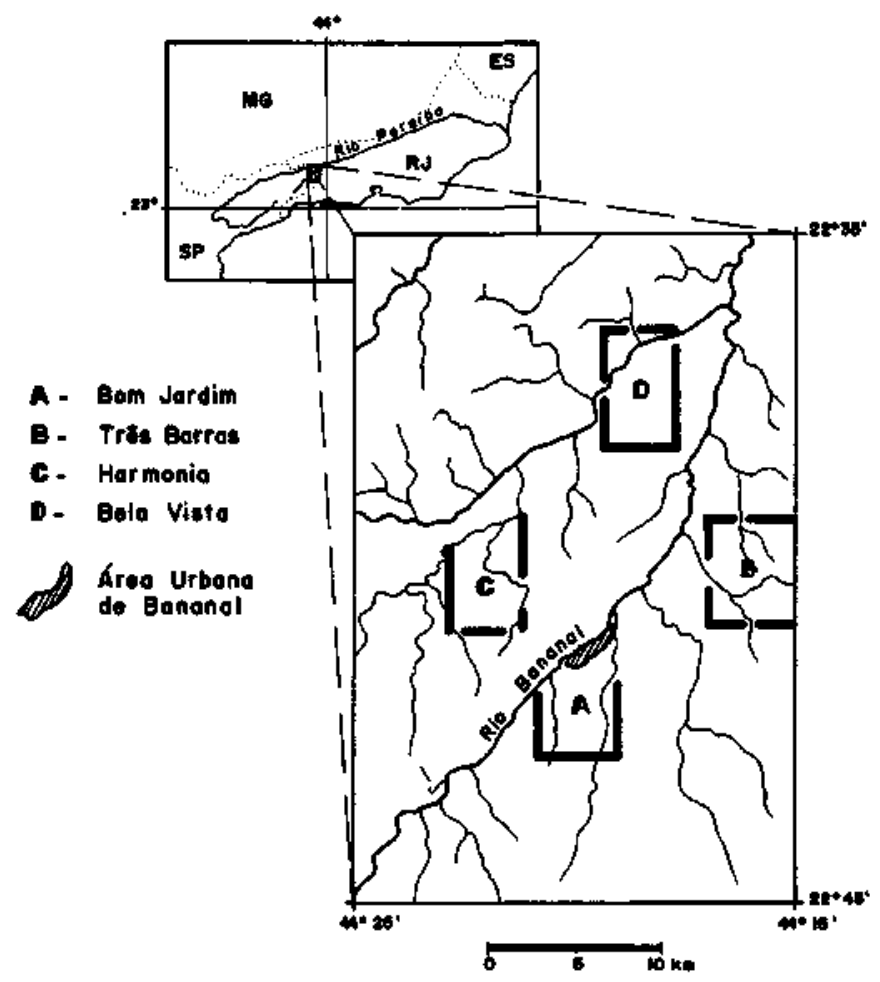

Figura 1-Localização das áreas de estudo

Figure 1 - Localization of study sites

Nesta região do Vale do Paraíba identificam-se duas unidades fisiográficas principais, representadas pelo domínio das colinas rebaixadas e pelo domínio montanhoso da Serra da Bocaina. Ressalta-se uma elevação gradativa dos topos das colinas em direção ao sopé da Bocaina, a partir do qual há um aumento da inclinação dos topos, configurandoos compartimentos topográficos de Bananal e Bocaina, respectivamente, com desnivelamentos maiores e menores que $200 \mathrm{~m}$.

O compartimento Bananal é composto predominantemente por segmentos de encosta convexo-côncavos, onde as unidades geomorfológicas côncavas representam apenas 29\%, aproximadamente, do relevo (Oliveira \& Meis 1985). Estes autores destacam que tais unidades concentram $66 \%$ das ocorrências de voçorocas, às quais associa-se a expansão da rede de canais. $\mathrm{O}$ avanço remontante das voçorocas co- nectadas à rede regional, por sua vez, é controlado por parâmetros morfométricos das próprias concavidades (Coelho Netto et al. 1988).

O mapeamento geológico (1:50.000) em andamento nos arredores de Bananal vem apresentando quatro unidades litológicas de idade pré-cambriana dispostas em largas faixas NE-SW com mergulho para NW, localmente cortadas por diques básicos (Almeida et al. 1989). Segundo o mapeamento (1:1.000.000) realizado pelo DNPM (1984), tais unidades pertenceriam ao Complexo Costeiro; entretanto, Machado et al (1983) as incorporam ao Complexo Paraíba do Sul. Almeida et al. (1989) descrevem essas quatro unidades destacando as seguintes rochas: unidade 1 - gnaisse com bandas feldspáticas, quartzosas e biotíticas, quartzo-muscovita xisto, anfibolitos, xistos máficos e ultra máficos; unidade 2 - granitóide porfirítico; unidade 3 - muscovita-biotita-hornblenda gnaisses com granada; e unidade 4 - gnaisse cálcio-silicático com intercalações de mármores, quartzitos e gonditos.

Os perfis de alteração do substrato rochoso podem atingir grandes espessuras, principalmente no domínio das colinas rebaixadas. As encostas são recobertas por mantos coluviais, os quais tendem a se espessar em direção aos eixos das concavidades e a ajustar-se na base local definida pelo fundo de vale adjacente. Os depósitos coluviais resultaram de ciclos de erosão-deposição nas encostas, durante o Quaternário Superior, o que deu origem à descontinuidades primárias e secundárias na estrutura subsuperficial dos materiais (Moura \& Meis 1986, Coelho Netto \& Dietrich 1991).

Embora Meis et al (1985) tenham sugerido uma relação entre as descontinuidades coluviais e o desencadeamento de voçorocamento nos eixos das concavidades, estudos mais recentes demostraram que essas descontinuidades não constituem um controle preponderante sobre a rede de fluxo d'água subsuperficiais e a ação erosiva (Coelho Netto et al 1988, Fernandes 1990). Esses últimos autores enfatizam o papel da topografia côncava na geração das descargas críticas dos fluxos d'agua subsuperficiais responsáveis pelo desenvolvimento de voçorocas, particularmente nos eixos das concavidades.

Originalmente, a região era recoberta pela Floresta Latifoliada Tropical (Brandalise et al 1976), sendo substituída no meado do século XVIII pela monocultura cafeeira que, ao atingir seu declínio, no início do século XX, dá lugar à instalação da pecuária extensiva. Hoje predomina um ambiente de pastagem, com coberturas de gramíneas e ocorrências isoladas de mata secundária. Ressalta-se que esse ambiente atual é propício à formiga "saúva", cuja atividade de escavação em profundidade no solo favorece a geração de pipeflow e, portanto, a recarga das zonas de saturação subsupercial (Coelho Netto et al. 1988 e Deus 1991).

MÉTODO DE TRABALHO Foram escolhidas inicialmente quatro áreas apresentando litologias distintas, de acordo com o trabalho de Almeida et al (1989) na escala 1:50.000, as quais estão localizadas na figura 1. As áreas Bela Vista e Harmonia situam-se sobre a unidade representada pelo muscovita-biotita-hornblenda gnaisse com granada, enquanto a área Três Barras está sobre o gnaisse com bandas feldspáticas, quartzosas e biotíticas associada a uma faixa de quartzo-muscovita xisto e a área Bom Jardim, disposta sobre o granitóide porfirítico.

Para a verificação da relação entre a orientação dos vales e a orientação das fraturas destas áreas, levantou-se em cartas topográficas (1:10.000) a orientação dos canais e, em campo, foram medidas as orientações, número e comprimento de fraturas presentes em círculos de $1 \mathrm{~m}$ de diâmetro, espaçados metro a metro sobre afloramentos de rocha sã ou alterada, naturais ou em cortes de estrada (Circle Inventory Method proposto por Davis 1984). A partir dessas medições, foram calculadas as densidades de comprimento e de número, seguindo o método acima citado. 
Tendo em vista um aprofundamento do conhecimento litológico devido à carência de detalhes em 1:50.000, nas áreas Três Barras e Bom Jardim, onde se procurou também ampliar as mensurações de fraturas segundo o método de Davis (1984). Tais áreas foram selecionadas por mostrarem uma variação acentuada nas respectivas densidades de fraturamentos, conforme será discutido adiante neste texto. Optou-se, nessa etapa de trabalho, por representar as fraturas por meio de rosetas, plotadas junto ao ponto de amostragem e indicando suas respectivas densidades de números e comprimento.

Finalmente, com base em fotografias aéreas 1:25.000 foram mapeadas as concavidades situadas nas áreas Bom Jardim e Três Barras, as quais foram agrupadas em dois tipos morfologicamente distintos: 1. concavidades mais profundas e com estreitamento na porção inferior; e 2. concavidades rasas e abertas na porção inferior. Os dois casos podem ocorrer ajustados diretamente aos fundos de vale adjacentes ou podem mostrar seus eixos suspensos em relação aos respectivos vales imediatamente adjacentes. A ocupação em área de cada grupo foi calculada para dar a representatividade dos mesmos. Ainda nesta mesma base foram obtidas as orientações dos eixos das concavidades do tipo 1 .

RESULTADOS E DISCUSSÕES Os valores médios de orientação dos canais, direção das fraturas e densidades de número e comprimento de fraturas, para as quatro áreas inicialmente amostradas, estão contidos na tabela 1. Verifica-se que a área com as mais elevadas densidades de fratura, Três Barras, não mostra uma relação proporcional entre as orientações de fraturas e canais, ao contrário das demais áreas com menores densidades.

Tabela 1 - Orientação de canais, orientações de fraturas e as respectivas densidades de número e de comprimento para as quatro áreas inicialmente amostradas, $n=$ número de amostras, $s=$ desvio padrão

Table 1 - Channel orientation, joint orientation and their respective densities by number and length, for the four sampled sites, $\mathrm{n}=$ is the sample number, $\mathrm{s}=$ standard deviation

TABELA DE VALORES MÉDIOS

\begin{tabular}{|c|c|c|c|c|}
\hline Área & $\begin{array}{l}\text { Orientação } \\
\text { dos canais }\end{array}$ & $\begin{array}{c}\text { Direção } \\
\text { das fraturas }\end{array}$ & $\begin{array}{c}\text { Densidade } \\
\text { de } \mathrm{N}^{2} \text { de } \\
\text { fraturas. } \\
10^{-6}\end{array}$ & $\begin{array}{l}\text { Densidade } \\
\text { de compri- } \\
\text { mento de } \\
\text { fraturas. } 40^{-4} \\
\left(\mathrm{~cm} / \mathrm{cm}^{2}\right)\end{array}$ \\
\hline $\begin{array}{l}\text { Bela } \\
\text { Vista }\end{array}$ & $\begin{array}{c}116^{\circ} \\
n=27 \mathrm{~s}= \\
46^{\circ}\end{array}$ & $\begin{array}{c}114^{\circ} \\
\mathrm{n}=78 \mathrm{~s} \\
43^{*}\end{array}$ & $\begin{array}{c}0,760 \\
n=18 \mathrm{~s}= \\
0,780\end{array}$ & $\begin{array}{c}0,020 \\
\square=18 \quad 5= \\
0,030\end{array}$ \\
\hline $\begin{array}{c}\text { Três } \\
\text { Bartas }\end{array}$ & $\begin{array}{c}99^{\circ} \\
n=40 \mathrm{~s} s= \\
59^{\circ}\end{array}$ & $\begin{array}{c}119^{\circ} \\
\mathrm{n}=151 \mathrm{~s}= \\
47^{\circ}\end{array}$ & $\begin{array}{c}1,820 \\
n=195= \\
1,460\end{array}$ & $\begin{array}{c}0,050 \\
\mathrm{a}=19 \mathrm{~s}= \\
0,040\end{array}$ \\
\hline \multirow[t]{2}{*}{$\begin{array}{l}\text { Bom } \\
\text { Jardim }\end{array}$} & $\begin{array}{c}110^{\circ} \\
n=45 \mathrm{~s}= \\
40^{\circ}\end{array}$ & $\begin{array}{c}104^{\circ} \\
n=32^{\circ} s= \\
58^{\circ}\end{array}$ & $\begin{array}{c}0,140 \\
\mathrm{n}=24 \mathrm{~s}= \\
0,140\end{array}$ & $\begin{array}{c}0,010 \\
n=24 \text { s } \\
0,010\end{array}$ \\
\hline & $103^{\circ}$ & $100^{\circ}$ & 0,460 & 0,020 \\
\hline
\end{tabular}

Para compreender melhor tal resultado, foi feito um estudo detalhado nas áreas Três Barras e Bom Jardim, pois apresentaram tendências opostas. Foram então elaborados mapas geológicos de detalhe juntamente com a ampliação da amostragem de fraturas.
O mapa geológico (1:10.000) da área Três Barras (Fig. 2) mostra a SE a ocorrência de um granitóide porfirítico (unidade 2). Acima dessa unidade e ocupando a maior parte da área, está presente o quartzo-muscovita xisto contendo veios pegmatíticos locais, guardando para um gnaisse com bandas feldspáticas, quartzosas e biotíticas (unidade 1.) No extremo NW da área volta a aparecer o granitóide porfirítico. Um dique básico, com cerca de $20 \mathrm{~m}$ de espessura, corta essas rochas. A foliação metamórfica segue as direções regionais, com direção $\mathrm{NW}$-SE e caimento variando de 20 a $75^{\circ}$ para NW. O fraturamento da área, indicando nas rosetas, distribui-se em quase todas as direções com mergulhos variando de 65 a $90^{\circ}$. Pontualmente, entretanto, há o predomínio de certas direções e variações de freqüência nas famílias de fraturas.

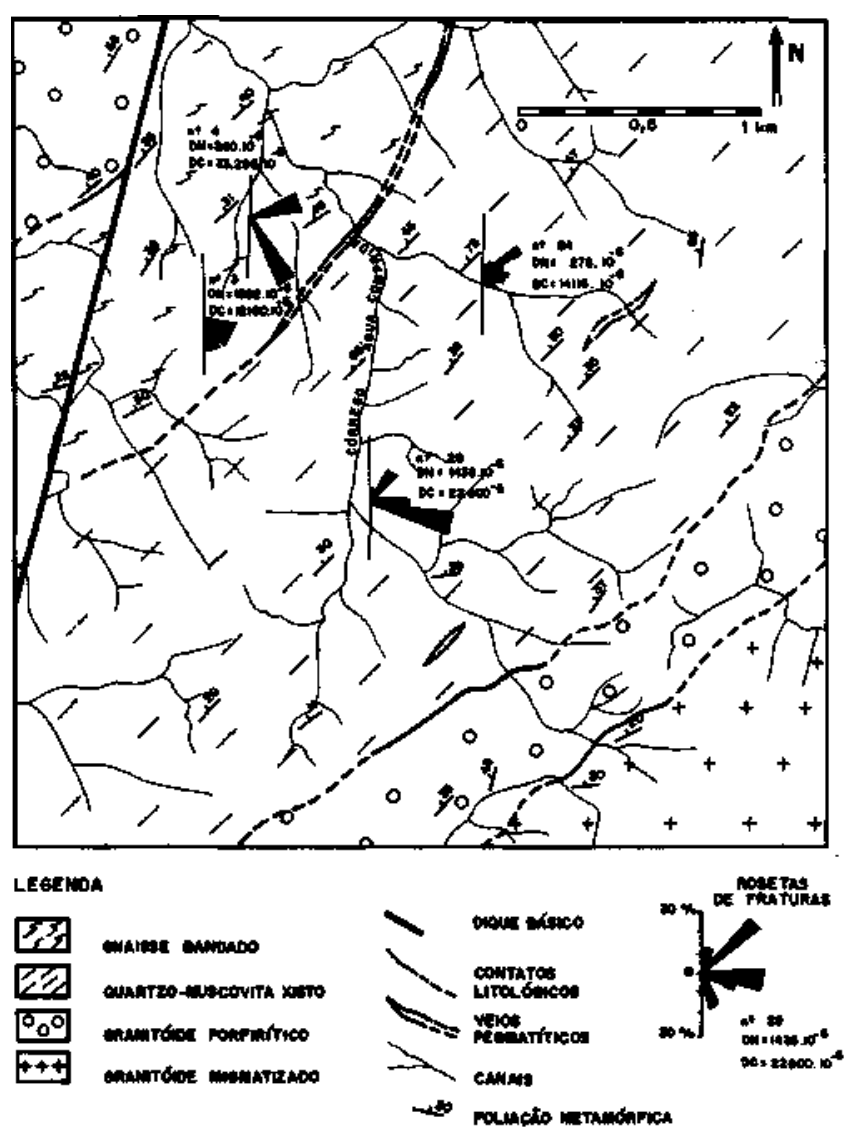

Figura 2 - Mapa geológico detalhado da área Três Barras, rosetas de orientação de fraturas com a indicação do número de círculos amostrados $\left(n^{\circ}\right)$, densidades de número $(D N)$ e de comprimento de $(D C)$ de fraturas

Figure 2 - Detaile geological map at Três Barras site, rose diagram of joints with indication of number of sampled circles $\left(n^{\circ}\right)$, density of joints by number (DN) and length (DC)

No mapa geológico (1: 10.000) da área Bom Jardim (Fig. 3), observa-se a SE a ocorrência do quartzo-muscovita xisto e do gnaisse bandado (unidade 1). Acima dessa unidade ocorre uma larga faixa do granitóide, por vezes com foliação melhor definida. Na porção NW da área, sobre o granitóide, encontra-se o muscovita-biotita-homblenda gnaisse com granada (unidade 3 ). A foliação metamórfica segue basicamente a atitude regional, direção NE-SW com mergulho de 20 a $70^{\circ}$ para NW, exceto quando forma dobras abertas, com superficie axial E-W sub vertical e com eixo caindo para $\mathrm{W}$ em torno de $15^{\circ}$. Nesta área, o fraturamento ocorre em todas as direções e há variações de freqüência nas famílias de fraturas. Uma falha com superficie subvertical atravessa toda a área na direção NNW-SSE. 


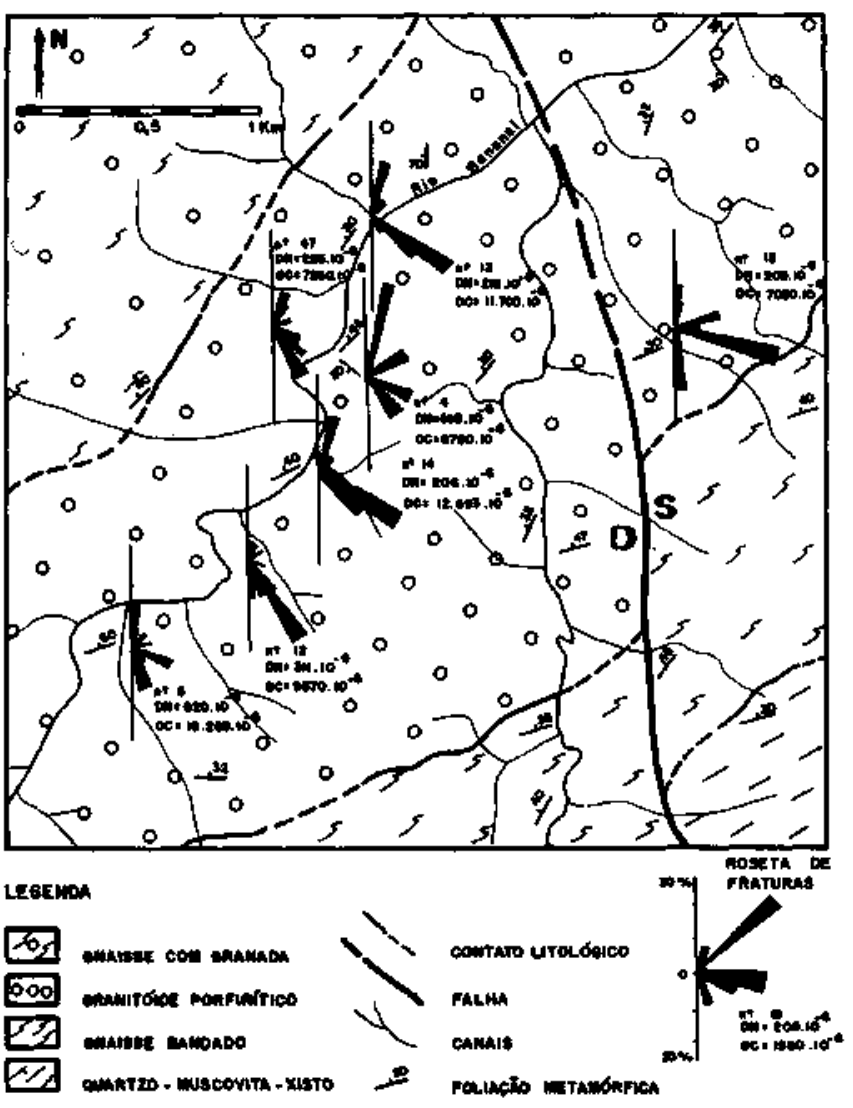

Figura 3 - Mapa geológico detalhado da área Bom Jardim, com rosetas de orientação de fraturas com indicação do número de círculos amostrados $\left(n^{\circ}\right)$, densidades de número $(D N)$ e de comprimento (DC) de fraturas

Figure 3 - Detailed geological map at Bom Jardim site, rose diagram of joints with indication of number of sampled circles $\left(\mathrm{n}^{\circ}\right)$, density of joints by number (DN) and length (DC)

Nos mapas geológicos apresentados (Fig. 2 e 3), observa-se com clareza a relação entre as orientações de fraturas e canais, embora não devam ser excludentes outras estruturas orientadoras da rede de drenagem, tais como contatos litológicos e a foliação metamórfica, como observado por outros autores (Agostinho 1969 e Lopes et al. 1989). Na área Três Barras, a direção de um dique básico é paralela ao canal de vale principal (Córrego Água Comprida). Já, na área Bom Jardim, o maior vale tributário ao Rio Bananal está orientado paralelamente a uma falha e o ponto de amostragem de fraturamento mais próximo a esta falha apresenta uma grande freqüência de fraturas paralelas à sua direção.

A figura 4 (A e B) mostra os histogramas de freqüência das orientações das famílias de fraturas medidas em campo e dos eixos de concavidades obtidos em base aerofotográfica $(1: 25.000)$, nas duas áreas estudadas. Nota-se que nas duas áreas as orientações abrangem uma ampla variação de distribuições. Entretanto, não se verifica uma relação direta entre os percentuais de freqüência das variáveis consideradas. Tal fato parece revelar uma certa especificidade na condição de fraturamento da rocha para afetar o desenvolvimento das concavidades. A interpretação aerofotográfica $(1: 25.000)$, aliada à observação de campo, permitiu o estabelecimento de uma tipologia morfológica das concavidades e o cálculo percentual de suas áreas de ocupação, conforme está resumido na tabela 2. Verifica-se que em ambas as áreas, o percentual de ocupação das concavidades é inferior ao valor regional de $29 \%$ apontado anterior-
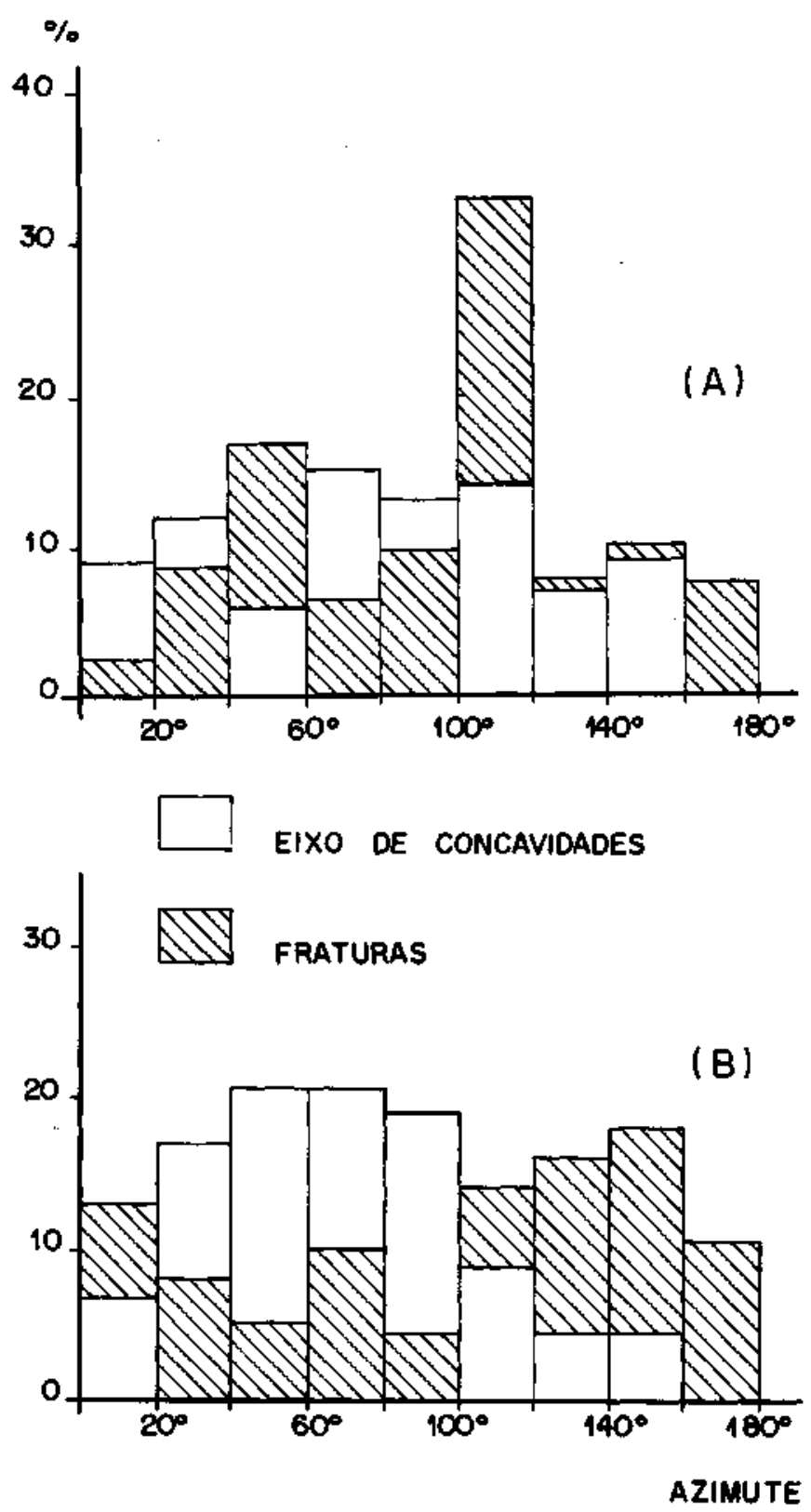

Figura 4 - Histograma de freqüência de orientações de fraturas e dos eixos das concavidades para as áreas Três Barras (A) e Bom Jardim (B)

Figure 4 - Orientation frequency histogram of joint and concavity axis at Três Barras (A) and Bom Jardim (B) sites

mente por Oliveira \& Meis (1985): na área Três Barras, o total das concavidades ocupa $18,2 \%$, enquanto na área Bom Jardim o percentual atinge apenas $15 \%$. As concavidades profundas e com estreitamento na porção inferior predominam sobre as concavidades rasas e abertas na porção inferior, nas duas áreas, mostrando-se, porém, mais freqüentes na área três Barras, onde ocorrem as maiores densidades de fraturas, conforme foi mencionado anteriormente.

Observações de campo indicam que os eixos das concavidades profundas e fechadas na porção inferior, geralmente acompanham as direções de fraturas vistas em afloramentos próximos e, muitas vezes, localizados no fundo das voçorocas que aí se desenvolvem. Além disso, este mesmo tipo de concavidade quando ocorre suspensa em relação ao fundo de vale adjacente, mostra, a jusante do estreitamento do seu eixo, a presença de túneis erosivos. Esses túneis se formam e evoluem 
Tabela 2 - Ocorrência de concavidades estruturais e nãoestruturais nas áreas Três Barras e Bom Jardim

Table 2 - Occurrence of structural and non-structural concavities at Três Barras and Bom Jardim sites

\begin{tabular}{|c|c|c|c|c|c|c|}
\hline \multirow[t]{2}{*}{ Área } & \multicolumn{2}{|c|}{$\begin{array}{l}\text { Concavidades } \\
\text { profundas com } \\
\text { estreitamento na } \\
\text { porção inferior }\end{array}$} & \multicolumn{2}{|c|}{$\begin{array}{l}\text { Concavidades } \\
\text { rasas com } \\
\text { abertura na } \\
\text { porçào inferior }\end{array}$} & \multicolumn{2}{|c|}{$\begin{array}{c}\text { Total das } \\
\text { concavidades }\end{array}$} \\
\hline & $\not{w}$ & $\begin{array}{l}N^{2} \text { de } \\
\text { casos }\end{array}$ & $\%$ & $\begin{array}{l}\mathrm{N}^{2} \text { de } \\
\text { casos }\end{array}$ & $\%$ & $\begin{array}{l}N^{2} \text { de } \\
\text { casos }\end{array}$ \\
\hline $\begin{array}{l}\text { Trés } \\
\text { Barras }\end{array}$ & 12,6 & 65 & 5,6 & 21 & 18,2 & 86 \\
\hline $\begin{array}{l}\text { Bom } \\
\text { Jardim }\end{array}$ & 9,5 & 41 & 5,5 & 17 & 15,0 & 58 \\
\hline
\end{tabular}

remontantemente no interior da rocha alterada, em paralelo à orientação do fraturamento local. A expansão dos túneis pode levar ao colapso de seu teto e, com a remoção dos materiais colapsados, formam-se sistemas descontínuos de canais, os quais tendem a interconectar-se no tempo. Tais observações reforçam os argumentos que indicam a associação entre esse tipo de concavidade e o fraturamento da rocha.

CONSIDERAÇÕES FINAIS Estudos anteriores apontam que a dissecação dos vales pela incisão de canais ou voçorocas nos eixos das concavidades associa-se aos mecanismos de poro-pressão em faces de exfiltração com descargas críticas de fluxos d'água subsuperficiais (Coelho Netto et al.
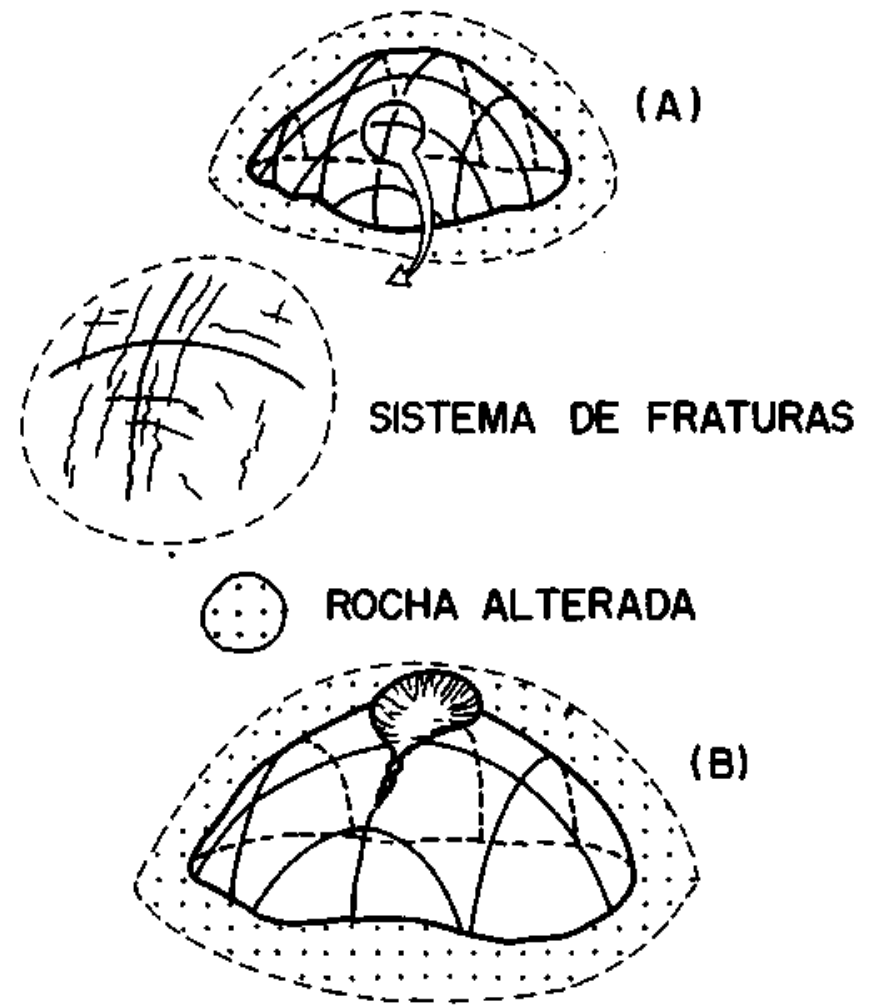

(B)

Figura 5 - Desenvolvimento de concavidades estruturais controladas por fraturas na rocha (A). Formação de canal e desenvolvimento inicial de uma concavidade suspensa em relação ao fundo de vale adjacente; (B). Fase de aprofundamento e recuo de encostas; $(\boldsymbol{C})$. Desenvolvimento de subunidades côncavas na interseção de duas famílias de fraturas (D)

Figure 5 - Development of structural concavities controled by joints in bedrock (A). Channel formation and inicial development of a hanging concavity, relative to the adjacent valley floor $(\mathbf{B})$. Downcutting and slope retreat phase (C). Developement of sub-concavities due to intersection of two sets of joints (D)
1988, Coelho Netto \& Fernandes 1990). Segundo os últimos autores citados, a expansão e o aprofundamento dos canais tendem a provocar o descalçamento das encostas circundantes e, assim, detonar ocorrências de deslizamentos (tipo slump) com superfícies de ruptura profundas e geralmente associadas às descontinuidades estratigráficas dos sedimentos quaternários ou à alteração diferencial das rochas subjacentes. Estes movimentos de massa, juntamente com a erosão superficial dos solos expostos na cicatriz erosiva e depósitos correlatives, tenderiam a promover o alargamento dos canais e, conseqüentemente dos vales. Observações de campo sugerem ainda que as concavidades rasas e abertas, conectadas aos canais, podem surgir do solapamento da base inferior das encostas laterais, por fluxos d'água canalizados, promovendo o descalçamentos das encostas e detonando deslizamento mais rasos. Outros mecanismos erosivos (por debris flow ou lavagem superficial), também poderiam responder pela geração dessas feições rasas e abertas, em particular, naquelas que ocorrem suspensas em relação aos vales adjacentes.

Sobre as concavidades profundas e com estreitamento na porção inferior, propõe-se um controle direto do fraturamento das rochas na sua formação e desenvolvimento, com base nos argumentos apontados neste texto. Sugere-se que o fraturamento das rochas, propiciando maior condutividade hidráulica em relação à matriz rochosa, tenderia a favorecer a percolação ascendente das águas subsuperficiais e, assim, sob condições de poro-pressão crítica na face de exfíltração, poderia ocasionar, pelo menos em parte, a formação dos túneis erosivos e conseqüente formação de canais. Na figura 5 , mostra-se, em desenho esquemático, uma seqüência de diagramas que representam a formação de canais ao longo de fraturas ou interseção de fraturas (Fig. 5A), seguindo-se a fase de recuo lateral e remontante sobre a área de contribuição por meio de transporte primário de materiais por movimentos de
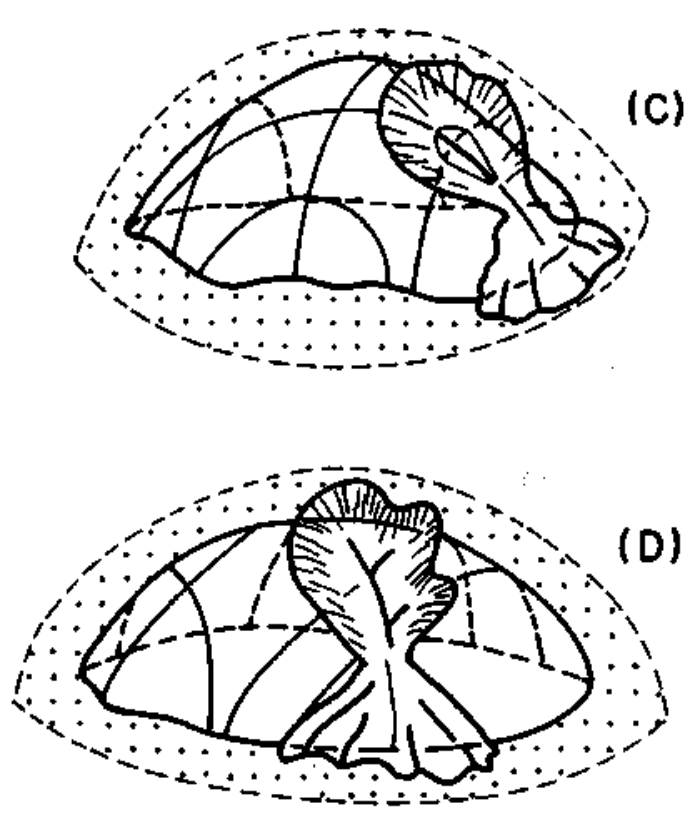
massa, dando origem à concavidade estruturalmente controlada pelo fraturamento (Fig. 5B). A interseção entre fraturas ou mesmo entre fraturas e a direção de unidades rochosas menos resistentes poderiam detonar a formação de concavidades tributárias (Fig. 5C). Assim, seria desenvolvido o sistema de concavidades não-canalizadas e canalizadas, em referentes ordens hierárquicas, reproduzindo a rede de drenagem fortemente controlada pelas estruturas do substrato geológico, tal como observado na área estudada.

O modelo conceitual ora proposto requer um maior conhecimento de campo sobre a relação entre fraturas, a hidrologia das encostas e as propriedades mecânicas dos materiais, de modo que se possa definir o modelo físico sobre a geração do canal inicial e seu local de iniciação. A presença do canal na encosta representaria a principal via de transferência dos materiais transportados por movimentos de massa e, secundariamente, também por lavagem superficial da cicatriz erosiva e dos materiais instabilizados, possibilitando o desenvolvimento lateral e remontante da concavidade, ou seja, a formação e evolução do vale. Os estudos hidrológicos, tal como proposto acima, já vêm sendo conduzidos na área Bom Jardim, em uma concavidade estrutural suspensa, que converge para uma bacia de segunda ordem tributária do Rio Bananal. Uma segunda unidade experimental deverá ser implantada na área Três Barras para fins de comparação do papel de fratura na hidrologia de encostas sob litologias distintas.

Agradecimentos Agradecemos a colaboração nas fases de campo e gabinete ao professor Júlio C.H. Almeida e aos colegas Eduardo S. Lopes Luís G. Silva e Marcelo Dantas. Ainda ao professor André Calixto pelo auxílio em fotogrametria, e ao Conselho Nacional de Desenvolvimento Científico e Tecnológico $(\mathrm{CNPq})$ pelo financiamento deste trabalho.

\section{REFERÊNCIAS BIBLIOGRÁFICAS}

AGOSTINHO, J. 1969. Observações sobre o sítio urbano de Bananal (Estado de São Paulo). Geomorfologia, (13):12-15.

ALMEIDA, J.C.H.; FERNANDES, N.F.; SILVA, L.G.E.; LOPES, E.S.; AVELAR, A.S. 1989. Perfil litoestrutural na região de Bananal - Arapeí, vertente norte da Serra da Bocaina (SP). In: SIMP. GEOL. SUDESTE, 1. Rio de Janeiro, 1989. Resumos... Rio de Janeiro, SBG/RJ-SP. p. 111-112.

ANDERSON, M.G. \& BURT, T.P. 1978. The role of topography in controlling throughflow generation. Earth Surface Processes \& Landforms, 3:331-334.

BRANDALISE, L.A.; RIBEIRO, J.H.; FERRARI, P.O. 1976. Projeto Vale do Rio Paraiba do Sul. Rio de Janeiro, DNPM/CPRM. 441 p. (Relatório Final).

BÜDEL, J. 1982. Climatic Geomorphology (Translated from Klima Geomorphologie, 1977). Princeton, Princeton Unviersity Press. 443 p.

COELHO NETTO, A.L. 1985. Surface Hydrology and Soil Erosion in a Tropical Mountainous Rainforest Drainege Basin, Rio de Janeiro. Belgium. 181 p. (PhD Thesis, Katholieke Universiteit Leuven)

COELHO NETTO, A.L. \& DIRTRICH, W.E. 1991. Ciclos de agradação e degradação no Médio Vale do Rio Paraíba do sul: datações absolutas. In: SIMP. GEOL. SUDESTE, 2. São Paulo, 1991. Atas... São Paulo, SBG/ SP-RJ.p. 33

COELHO NETTO, A.L. \& FERNANDES, N.F. 1990. Hillslope erosionsedimentation and relief inversion in SE Brazil. In: FIJI SYMPOSIUM, RESOURCE NEEDS APLICATION TO REDUCE EROSION \& SEDIMENTATION IN TROPICAL STEEPLANDS. Fiji, 1990. Proceedings... Fiji, IAHS Publication, (192):174-182.

COELHO NETTO, A.L.; FERNANDES, N.F.; DEUS, C.E. 1988. Gullying in the Southeastern Brazilian Plateau, SP. In: PORTO ALEGRE SYMPOSIUM, SEDIMENTS BUDGETS. Porto Alegre, 1988. Proceedings... Porto Alegre IAHS Publication. (174):35-42.

COELHO NETTO, A.L. \& SANTOS, A.A.M. 1979. Análise de freqüência das chuvas no Maciço de Tijuca, RJ. Rev. bras. Hidrol. Rec. Hídricos, 2:3-18.

DAVIS, G.H. 1984. Structural Geology of Rocks and Regions. New York, Wiley \& Sons. $492 \mathrm{p}$.

DAVIS, W.M. 1900. Glacial erosion in France, Switzerland and Norway. Proc. Boston Soc. Nat. \& Hist., (29):273-322.

DEUS.C.E. 1991. O Papel da Escavação das Formigas do Gênero ATTAna Hidrologia das Encostas em Áreas de Pastagem: Bananal (SP). Rio de Janeiro. 253 p. (Dissertação de Mestrado, IG/UFRJ).

DIETRICH, WE.; WILSON, C.; RENEAU, S. 1986. Hollows, colluvium and landslides in soil-mantled landscapes. In: ABRAHAMS, A.D. ed. Annual Binghanton Symposium in Geomorphologie, 16, Hillslope Processes. London, Allen \& Unwin. p. 361-388.

DEPARTAMENTO NACIONAL DA PRODUÇÃO MINERAL 1984. Geologia do Brasil. Rio de Janeiro, DNPM. p. 309-313.

DUNNE, T. 1970. Runoff production in a humid area. U.S. Dept. Agric. Report, ARS:41-160.

DZULYNSKI, K.S. \& PEKALA, K. 1980. Bogcirques and solfluction valley in granitic rocks. Zeits. Geomorp., 24(2):219-235.

FERNANDES, N.F. 1990. Hidrologia Subsuperficial e Propriedades Físico Mecânicas dos "Complexos de Rampa". Rio de Janeiro. 160 p. (Dissertação de Mestrado, IG/UFRJ).
HACK, J.T. 1960. Interpretation of erosion topography in humid temperated regions. Am. J. Sci., 258A:80-97. (Bradley volume).

HACK, J.T. \& GOODLET, J.C. 1960. Geomorphology and Forest Ecology of a Mountain Region in the Central Apallachians. Washington, U.S. Geol. Survey. 66 p. (Prof. Paper 347).

HORTON, R.E. 1945. Erosion development of streams and their drainage basins: hydrophysical approach to quantitative morphology. Geol. Soc. Am. Bull, 59:275-370.

LOPES, E.S.; AVELAR, A.S.; DEHLER, N.M.; FERNANDES, N.F.; COELHO NETTO, A.L. 1989. Condicionantes lito-estruturais no desenvolvimento da rede de drenagem: Médio Vale do Rio Paraíba do Sul. In: SIMP. GEOL. SUDESTE, 1. Rio de Janeiro, 1989. Resumos... Rio de Janeiro, SBG/RJ-SP. p. 28-29.

MACHADO, L., P; RIBEIRO, M. W; GONZALES, S.R.; SCHENINI, C.A.; NETO, A.S.; PALMEIRA, R.C.B; PIRES, J.L; TEIXEIRA, W; CASTRO, H.E.F. 1983. Projeto Rodam Brasil, Folhas S.F. 23/24, Rio de Janeiro/Vitória. Brasília. 400 p. (Levantamento de Recursos Naturais 32 ).

MCKEL, R. 1974. Dambos: a study in morphodynamic activity on the plateau regions of Zambia. Catena, 1:327-365.

MEIS, M.R.M. \& MONTEIRO, A.M.F. 1979. Upper Quaternary "rampas": Doce river valley, SE Brazillian Plateau. Zeits. Geomorp., 23:132-151.

MEIS, M.R.M.; COELHO NETTO, A.L.; MOURA, J.R.S. 1985. As descontinuidades nas formações coluviais como condicionantes nos processo hidrológicos e de erosão acelerada. In: SIMP NAC. DE CONTROLE DE EROSÃO, 3. Maringá, 1985. Anais... Maringá, ABGE. p. 75-87

MEIS, M.R.M.; COELHO NETTO, A.L.; OLIVEIRA, P.T.T.M. 1981. Ritmo e variabilidade das precipitações no vale do Rio Paraíba do Sul: o caso de Resende. Rev. Bras. Hidrol. Rec. Hídricos, 3:43-56.

MILLS, H.H. 1989. Hollow form as function of boulder size in the Valley and Ridge Province, Southwestern Virginia. Geology, 17(7):595-598.

MONTGOMERY, D.R. \& DIETRICH, WE. 1988. Where do channels begin?. Nature, 336(6196):232-234.

MOURA, J.R.S. \& MEIS, M.R.M. 1986. Contribuição à estratigrafia do Quaternário Superior no Médio Vale do Rio Paraíba do Sul, Bananal, SP. An. Acad. bras. Cienc., 58(1):89-102.

OLIVEIRA, M.A. \& MEIS, M.R.M. 1985. Relações entre a geometria do relevo e formas de erosão linear acelerada, Bananal, SP. Bol. IG/USP, 4:87-99.

TSUKAMOTO, Y.; OTHA, T; NOGUCHI, H. 1982. Hydrological and geomorphological studies of debris slides on forested hillslops in Japan. In: EXTER SYMPOSIUM. Exter, 1982. Proceedings... Exter, IAHS. (137):89-98.
MANUSCRITO A703

Recebido em 24 de julho de 1991

Revisão de 20 de novembro de 1991 Revisão aceita em 20 de dezembro de 1991 